\title{
Modification of potato starch with adipic acid and research of modification product as raw materials for food biodegradable packaging
}

\author{
Sergii Shulga, Oksana Shulga, Natalya Simurova
}

\author{
National University of Food Technologies, Kyiv, Ukraine
}

\section{Keywords: \\ Potato starch \\ Adipic acid \\ FT-IR \\ NMR \\ X-Ray \\ Packaging \\ Ecological \\ Biodegradable}

\section{Article history:}

Received

29.03.2021

Received in

revised form

03.09.2021

Accepted

30.09.2021

\section{Corresponding} author:

Oksana Shulga

E-mail:

shulgaos@ukr.net

DOI:

$10.24263 / 2304-$

974X-2021-10-3-

10

\section{Abstract}

Introduction. The aim of our work was to study the modification of potato starch with adipic acid chloride in order to further physicochemical study of the obtained product and use, for example, as an effective film former of biodegradable films/coatings.

Materials and methods. Potato starch, adipic acid (E 355), thionyl chloride. Solvents - DMSO, DMF, methanol, ethanol. IR spectroscopy was performed on a Nexus-475 Nicolet device. NMR spectra were recorded by NMR spectrometer Mercury, VARIAN. Xray diffraction analysis was carried out by the DRON-3M device in $\mathrm{CuK} \alpha$ emission with $\mathrm{Ni}$ filter; $U=35 \mathrm{kV}, I=20 \mathrm{~mA}$; counterdisplacement angle $\Delta 2 \Theta$ is $0,04^{\circ}$; time of intensity reckoning is $3 \mathrm{~s}$. Thermogravimetric study was performed on the device Q1500B.

Results and discussion. There are no signals of the acyl chloride group (1785-1815 $\mathrm{cm}^{-1}$ ) and signals of hydrolysis products of adipic acid chloride, namely the fluctuation band of carboxylic acid group $v C=O\left(1750-1770 \mathrm{~cm}^{-1}\right.$ and their salts $\left.1640 \mathrm{~cm}^{-1}\right)$ in the IR spectrum This gives reason to believe that the crosslinking of glucopyranose rings occurred due to the reaction of both acid chloride groups. The elemental analysis results of acylated potato starch with adipic acid chloride are as follows: found Carbon $42.33 \%$, Hydrogen $-6.65 \%$; $\mathrm{C}_{54} \mathrm{H}_{86} \mathrm{O}_{42}$. Calculated $41.96 \%$ for Carbon and $6.58 \%$ for Hydrogen. The thermographimetric analysis results indicate that the modification of potato starch with adipic acid chloride causes a change in the shape and amount of potato starch water. NMR research did not determine the degree of starch glucopyranose chains crosslinking and the position of the substituent. The native starch Xray showed that the degree of native starch crystallinity is $12 \%$. Modification of potato starch with adipic acid reduces the degree of crystallinity to $5 \%$. In addition, the destruction of the primary (crystalline) structure of the starch grains was also confirmed by optical microscopy.

Conclusions. The modified product has a number of different characteristics from the original product. The use of starch as a natural substance that is capable of biodegradation makes it possible to is recommend the resulting product as a raw material for environmentally friendly packaging materials. 


\section{Introduction}

Modification of starch allows to change its physical and chemical properties and to create new materials with the set properties (Kryazhev V. N. et al., 2010). Starch, modified chloride, phosphate, sulfuric acid, acetic anhydride, acetic and succinic acid, potassium hydroxide, ammonium persulfate propionic acid chloride (Hui Chi et al. 2008) acetyl chloride malic acid (Shulga O.S. et al., 2018) etc. are produced industrially (Shulga O. et al. 2018).

A significant amount of work concerns the interaction of starch different types (Bhosale R. et al., 2006) with fatty acid chlorides (Fathi F. et al., 2014; Junistia L. et al. 2008). In addition, materials based on native and modified starch are biodegradable and are therefore used as environmentally friendly packaging materials (Suvorova A. I. et al., 2000). It is important to expand the range of raw materials for environmentally friendly packaging materials (Chorna A. I. et al., 2016).

The modification reaction occurs, as a rule, due to the interaction of starch with anhydrides and acid chlorides in organic solvents - pyridine, toluene, dimethylformamide, N, N-dimethylacetamide (Fan, Y. et al., 2020). However, organic solvents are toxic and difficult to remove from the final product, which prevents its use in the food and pharmaceutical industries. Some authors (Shulga O. S. et al., 2017) propose a method for the synthesis of esters of fatty acids of starch without solvents as the most effective, but this method has its drawbacks (incomplete interaction, reaction by-products remain in the reaction mixture, poor crystallization of reaction products, etc.).

According to the literature data (Kryazhev V. N. et al., 2010), most of the proposed schemes for the polysaccharides modification are multi-stage, complex, require expensive and toxic reagents, which is unacceptable for the food industry. All of the above complicates the implementation of new modified starch derivatives. Thus, the starch modification potential is far from exhausted.

A convenient method for modifying starch with adipic acid chloride using dimethyl sulfoxide as a solvent is proposed (DMSO). This effective solvent, which is widely used in organic synthesis, has a number of advantages, the main of which is its complete solubility in water, which allows you to completely remove its residues after the reaction, in addition, DMSO has low toxicity, is used as a drug in pharmaceuticals, for example, as part of the antiinflammatory drug "Dimexid".

Therefore, the work in the field of starch modification is relevant and continues in order to obtain starch with the specified technological properties. The issue of improving the modification method, which should not be complicated and cost-effective, is also relevant.

The modification of natural polymers has a positive effect on the properties of the polymer as a raw material for biodegradable materials based on previous research (Aburto J. et al., 1999).

The aim of our work was to study the modification of potato starch with adipic acid chloride in order to further physicochemical study of the obtained product and use, for example, as an effective film former of biodegradable films/coatings. 


\section{Materials and methods}

\section{Materials}

The research subject is modificaced potato starch. In order to make modifications were used potato starch, adipic acid (E 355), thionyl chloride, solvents - DMSO, DMF, methanol, ethanol.

The starch was prepared as follows: $100.02 \mathrm{~g}$ of potato starch was placed in a $500 \mathrm{~cm}^{3}$ flask, connected to a water jet pump and heated on a boiling water bath for 8 hours. Product yield: $88.00 \mathrm{~g}$ (loss due to drying $12 \%$ ).

\section{Preparation of DMSO}

$300 \mathrm{~cm}^{3}$ of DMSO was kept over calcined at the temperature of $400{ }^{\circ} \mathrm{C} \mathrm{CaO}$ for 2 days. Next, DMSO was transferred to a $500 \mathrm{~cm}^{3}$ flask and $30 \mathrm{~cm}^{3}$ of dry benzene was added. Residual water was distilled off at atmospheric pressure as an azeotrope with benzene, then DMSO was distilled in a vacuum water jet pump.

\section{Synthesis of adipic acid chloride}

$29.2 \mathrm{~g}(0.2 \mathrm{M})$ of adipic acid were placed in a $100 \mathrm{~cm}^{3}$ reactor equipped with a heated magnetic stirrer, a dropping funnel, a thermometer and a reflux condenser with a gas meter and a gas discharge tube. $53.5 \mathrm{~g}(0.45 \mathrm{M})$ of thionyl chloride were added in small portions with stirring through a dropping funnel. Calm gas evolution and slight heating of the reaction mass were observed. After $1 \mathrm{~h}$, three drops of DMF were added, and the temperature was maintained at $50-60{ }^{\circ} \mathrm{C}$ for another $5 \mathrm{~h}$. Excess thionyl chloride was distilled off in a vacuum water jet pump. Obtained $34.6 \mathrm{~g}(94.5 \%)$ of product, which was used without further purification.

\section{Esterification of starch with adipic acid chloride}

$9 \mathrm{~g}(0.05 \mathrm{M}$ based on glucose $)$ of dried starch and $300 \mathrm{~cm}^{3}$ of dried DMSO were placed in a $500 \mathrm{~cm}^{3}$ three-necked reactor equipped with a heated magnetic stirrer, a dropping funnel, a thermometer and a reflux condenser with a gas meter and a gas discharge tube. Stirred for $3 \mathrm{~h}$ at $70{ }^{\circ} \mathrm{C}$ to form a clear colorless gem. Next, heat was removed and $0.5 \mathrm{~g}$ of $\mathrm{K}_{2} \mathrm{CO}_{3}$ (approximately $2 \%$ by weight of starch) was added. $27.5 \mathrm{~g}(0.15 \mathrm{M})$ of adipic acid chloride were added dropwise with stirring. The reaction mass thickened, after $1 \mathrm{~h}$ the reaction mass was a very thick gem of light yellow color. The mixture was heated with stirring for another $2 \mathrm{~h}$ for temperatures $50-60{ }^{\circ} \mathrm{C}$. The reaction mixture was left overnight at room temperature. Then $200 \mathrm{~cm}^{3}$ of methanol was added and stirred vigorously for $1 \mathrm{~h}$. The precipitated white precipitate was filtered off under vacuum with a water jet pump and washed with distilled water $\left(2 \times 50 \mathrm{~cm}^{3}\right)$ and ethanol $\left(2 \times 50 \mathrm{~cm}^{3}\right)$. The resulting product was dried in air at room temperature.

\section{Research methods}

FT-IR. Infrared studies conducted on the device Nexus - 475 firm Nicolet, KBr tablet (Chung, C. et al., 2004). 
XRD. X-ray diffraction analysis was carried out by the DRON-3M device in $\mathrm{CuK} \alpha$ emission with Ni filter; $\mathrm{U}=35 \mathrm{kV}, \mathrm{I}=20 \mathrm{~mA}$; counterdisplacement angle $\Delta 2 \Theta$ is $0,04^{\circ}$; time of intensity reckoning is $3 \mathrm{~s}$ (Namazi H. et al., 2010).

TGA. TGA (Thermogravimetric Analysis) research was carried out by the Q-1500B device, at a heating rate of $20^{\circ} \mathrm{C} / \mathrm{min}$ (Prime R. B. et al., 2009).

NMR. NMR spectra were recorded by the Mercury NMR spectrometer, Varian, 400MHz in DMSO-d6 (Namazi H. et al., 2010).

\section{Results and discussion}

\section{IR research}

The changes that occurred as a result of the acylation reaction of potato starch with adipic acid chloride are confirmed by a number of factors. Thus, in the IR spectrum of modified starch (Figure $1 \mathrm{~b}$ ) appeared a maximum at $1710.82 \mathrm{~cm}^{-1}$, which is characteristic of $\mathrm{C}=\mathrm{O}$ in the ester group, which appeared in the modified starch as a result of the acylation reaction.

In the spectrum of native starch (Figure 1) and there is a fairly wide intense band, which is at $3389.35 \mathrm{~cm}^{-1}$, and in the spectrum of the modified sample (see Figure $1 \mathrm{~b}$ ) the band lies in the region of stronger fluctuations at $3411.08 \mathrm{~cm}^{-1}$, which is due with the degree of participation of the $\mathrm{OH}$ group in the formation of hydrogen bonds. The more hydroxyl groups involved in the formation of hydrogen bonds (native starch), the greater the range of their oscillations is shifted to a weak field. It is known (Silversteyn R. et al., 2011), that the position and nature of the band depends on the participation degree of the hydroxyl group in hydrogen bonds. In addition, when comparing the IR spectra of native and modified starches (Figure $1 \mathrm{a}, \mathrm{b}$ ) it was found that the spectra have different fluctuations in the uncharacteristic region.

The IR spectrum of native starch (Figure 1 a) contains a number of oscillations in the uncharacteristic region, in particular $981.1 \mathrm{~cm}^{-1}, 763.63 \mathrm{~cm}^{-1}, 573.42 \mathrm{~cm}^{-1}$.

When comparing these data, it is obvious that in the spectrum of native starch the oscillation frequency at $981.81 \mathrm{~cm}^{-1}$ increased and in the spectrum of modified starch lies at $1023.75 \mathrm{~cm}^{-1}$, the band with an oscillation frequency of $763.63 \mathrm{~cm}^{-1}$ shifted to $912.93 \mathrm{~cm}^{-1}$, and the band with an oscillation frequency of $573.42 \mathrm{~cm}^{-1}$ shifted to $631.13 \mathrm{~cm}^{-1}$, indicating a change in the uncharacteristic region of the spectrum of the sample of native starch after acylation. There are no signals of the acyl chloride group $\left(1785-1815 \mathrm{~cm}^{-1}\right)$ and signals of hydrolysis products of adipic acid chloride, namely the fluctuation band of carboxylic acid group $\mathrm{vC}=\mathrm{O}\left(1750-1770 \mathrm{~cm}^{-1}\right.$ and their salts $\left.1640 \mathrm{~cm}^{-1}\right)$ in the IR spectrum. This gives reason to believe that there was a crosslinking of glucopyranose rings, due to the reaction of both acid chloride groups.

Therefore, according to the IR analysis results, the sample of native and modified starches have different chemical composition as a result of potato starch chemical modification with adipic acid chloride. 

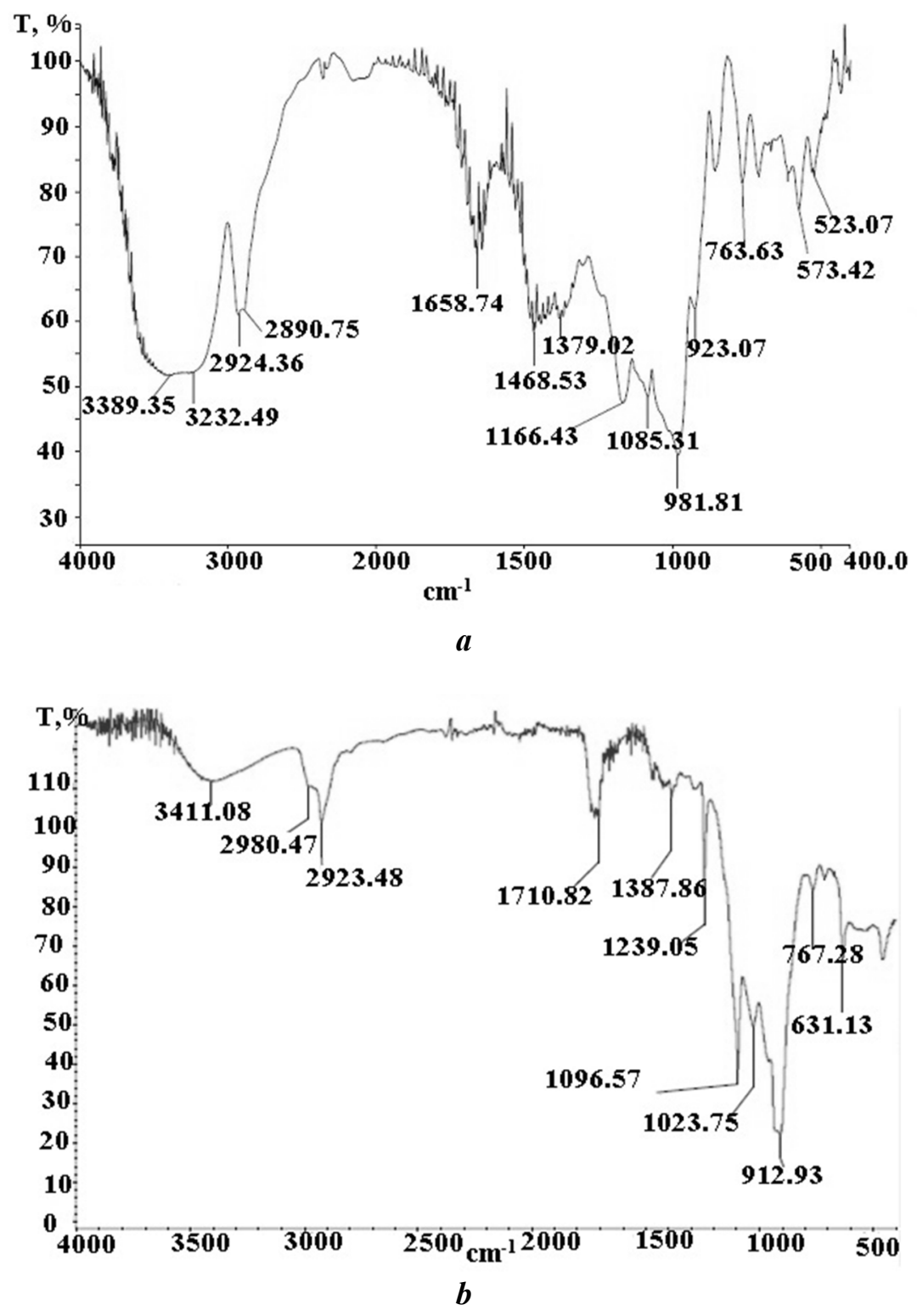

Figure 1. IR spectra of native (a) and modified (b) potato starch 


\section{Elemental analysis}

The results of acylated potato starch elemental analysis with adipic acid chloride are as follows: found Carbon 42.33\%, Hydrogen - 6.65\%; $\mathrm{C}_{54} \mathrm{H}_{8} \mathrm{O}_{42}$. Calculated Carbon $41.96 \%$, Hydrogen $-6.58 \%$.

The results of IR spectra (see Figure 1) and elemental analysis show that the acylation of starch with adipic acid chloride occurred due to crosslinking of starch glucopyranose chains with adipic acid chloride at the ratio of adipic acid chloride one molecule.

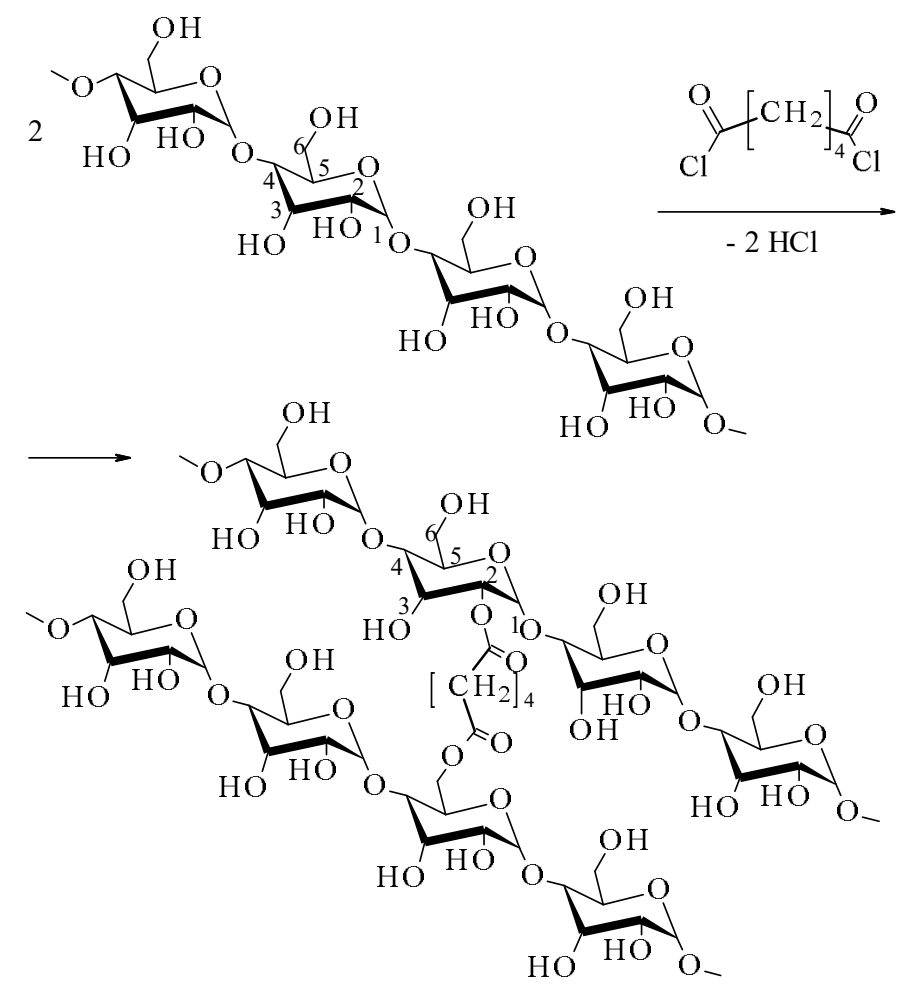

Figure 2. Structural formula of the potato starch modification product with adipic acid chloride

According to Patent by Vesa Myllymaki, Reijo Aksela the most easily acylated primary alcohol group and hydroxyl alcohol group at $C_{2}$. The authors (Junistia L. et al., 2008) prefer the hydroxyl group at $\mathrm{C}_{2}$. 


\section{Thermogravimetric reaserch}

If the crystalline to amorphous structure changes, the properties of the substance to bind and retain water can be expected to change. Using thermal analysis results obtained TGA are shown in Table 1.

Table 1

Zones of thermolysis of native and modified starches

\begin{tabular}{|c|c|c|c|c|c|c|c|c|c|c|}
\hline \multirow{4}{*}{ 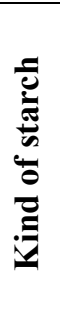 } & \multicolumn{10}{|c|}{ Thermolysis zones } \\
\hline & \multirow{2}{*}{\multicolumn{2}{|c|}{$\begin{array}{c}\text { I } \\
\text { Adsorbed water }\end{array}$}} & \multirow{2}{*}{\multicolumn{2}{|c|}{$\begin{array}{c}\text { II } \\
\text { Crystallization } \\
\text { water }\end{array}$}} & \multicolumn{4}{|c|}{ III } & \multirow{2}{*}{\multicolumn{2}{|c|}{$\begin{array}{c}\text { IV } \\
\text { Burning } \\
\text { char }\end{array}$}} \\
\hline & & & & & \multicolumn{2}{|c|}{$\begin{array}{c}\text { Thermolysis of } \\
\text { anhydrous } \\
\text { products }\end{array}$} & \multicolumn{2}{|c|}{ Charring } & & \\
\hline & $\begin{array}{l}\mathrm{t}_{\mathrm{s}}-\mathrm{t}_{\mathrm{f}} \\
{ }^{\circ} \mathrm{C}\end{array}$ & $\Delta \mathrm{m}, \%$ & $\begin{array}{l}t_{s}-t_{f} \\
{ }^{\circ} \mathrm{C}\end{array}$ & $\begin{array}{l}\Delta \mathrm{m}, \\
\%\end{array}$ & $\begin{array}{l}\mathrm{t}_{\mathrm{s}}-\mathrm{t}_{\mathrm{f}} \\
{ }^{\circ} \mathrm{C}\end{array}$ & $\begin{array}{l}\Delta \mathrm{m}, \\
\%\end{array}$ & $\begin{array}{l}\mathrm{t}_{\mathrm{s}}-\mathrm{t}_{\mathrm{f}} \\
{ }^{\circ} \mathrm{C}\end{array}$ & $\begin{array}{l}\Delta \mathrm{m}, \\
\%\end{array}$ & $\begin{array}{l}\mathrm{t}_{\mathrm{s}}-\mathrm{t}_{\mathrm{f}} \\
{ }^{\circ} \mathrm{C}\end{array}$ & $\begin{array}{l}\Delta \mathrm{m}, \\
\%\end{array}$ \\
\hline 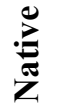 & $\begin{array}{l}65- \\
100\end{array}$ & 3.8 & $\begin{array}{l}100- \\
140\end{array}$ & 3.8 & $\begin{array}{c}300- \\
380\end{array}$ & 57.5 & $\begin{array}{l}380- \\
500\end{array}$ & 15.0 & $\begin{array}{l}500- \\
600\end{array}$ & 17.5 \\
\hline 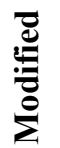 & $\begin{array}{l}60- \\
100\end{array}$ & 4.9 & $\begin{array}{l}100- \\
240\end{array}$ & 13.3 & $\begin{array}{l}240- \\
370\end{array}$ & 46.5 & $\begin{array}{c}370- \\
500\end{array}$ & 13.8 & $\begin{array}{c}500- \\
670\end{array}$ & 21.5 \\
\hline
\end{tabular}

$\mathrm{t}_{\mathrm{s}}-\mathrm{t}_{\mathrm{f}}-$ temperature range of thermolysis zones

According to the results of Table 1 modified starch contains more adsorbed water by $1.1 \%$ due to the modification in an aqueous medium and it is due to this that the amount of crystallization water in the modified starch is $9.5 \%$ higher. During the modification, the starch is gelatinized, and if it is crosslinked, water is retained. It is due to the presence of crystallization water in the modified starch that the anhydrous products amount is less and, as a consequence, in the third thermolysis zone the anhydrous products amount is $10 \%$ less than for native starch. In addition, the thermolysis of anhydrous products begins at slightly lower temperatures of $240{ }^{\circ} \mathrm{C}$, against $300{ }^{\circ} \mathrm{C}$ for native starch. Therefore, the potato starch modification with adipic acid chloride causes a change in the shape and amount of potato starch water.

\section{NMR reaserch}

There are 2 peaks, which are at $1498 \mathrm{ppm}$ and 2,203 ppm (Figure 3) which indicates the glucopyranose chains crosslinking. The first peak at $1.498 \mathrm{ppm}$ due to the methylene group appearance, which is in the $\alpha$-position relative to the carbonyl group and as a result of the screen shifts to a stronger field. The second peak at $2.203 \mathrm{ppm}$ is caused by other methylene groups, which also confirms the potato starch modification with adipic acid chloride. It was impossible to determine the glucopyranose crosslinking degree chains of starch, as well as to determine the substituent position by NMR spectra. 

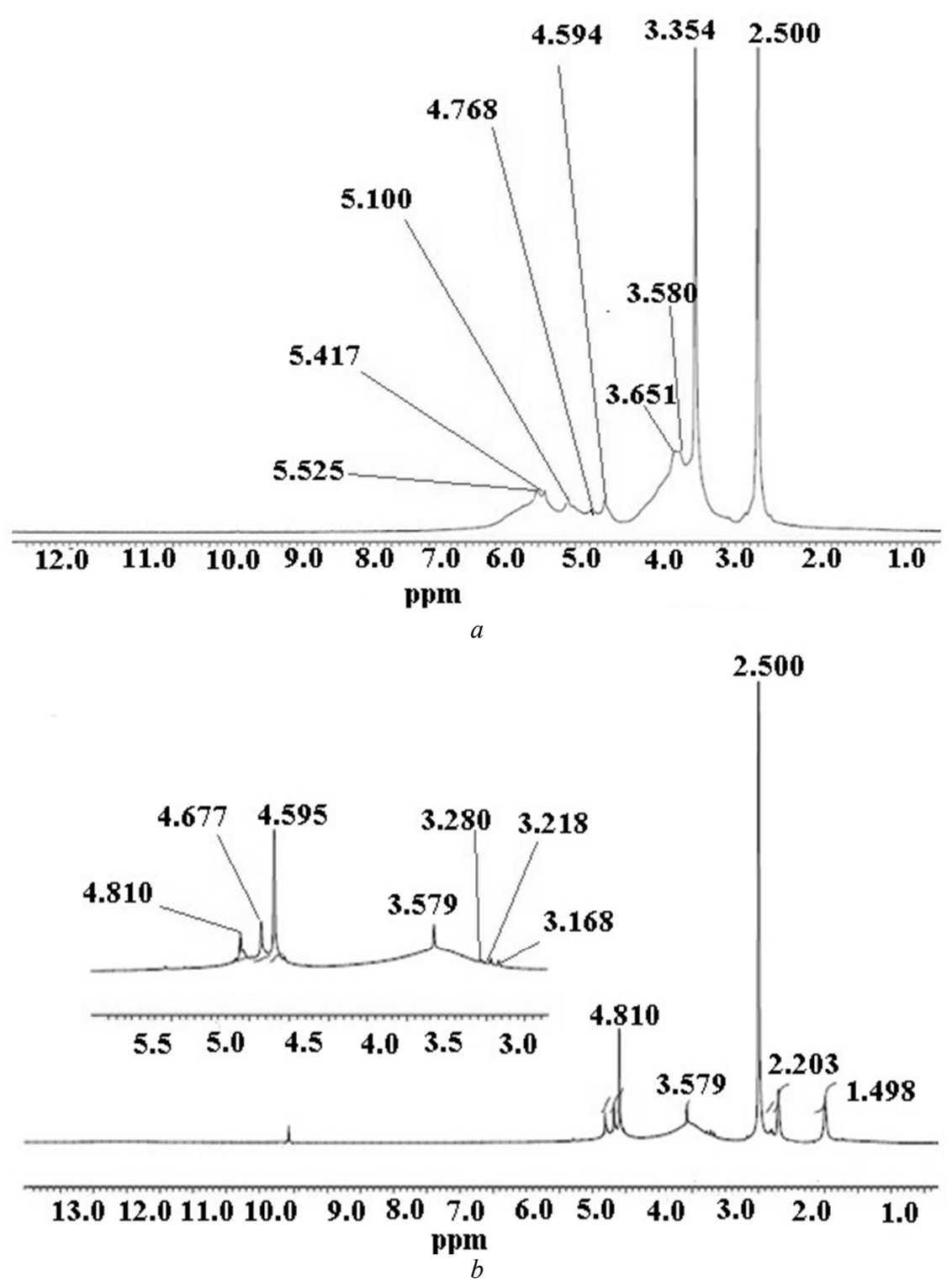

Figure 3. NMR spectra of native potato starch (a) and modified with adipic acid chloride (b) $(n=3, p \leq 0,05)$ 


\section{- Food Technology}

\section{X-Ray structural study}

In order to determine the effect of the adipic acid chloride esterification process on the crystallinity of the potato starch structure. The obtained diffraction patterns are shown in Figure 4.

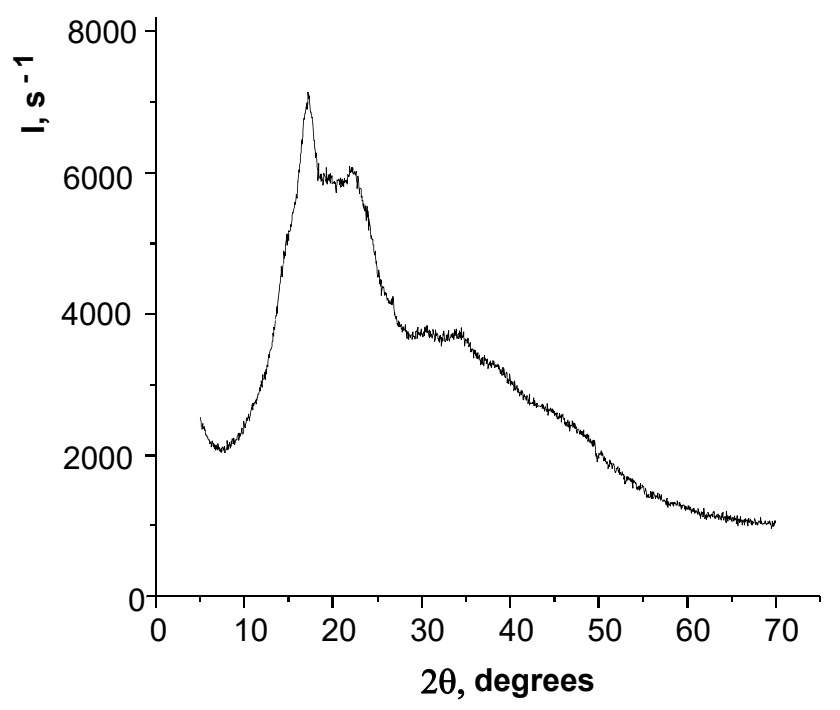

$a$

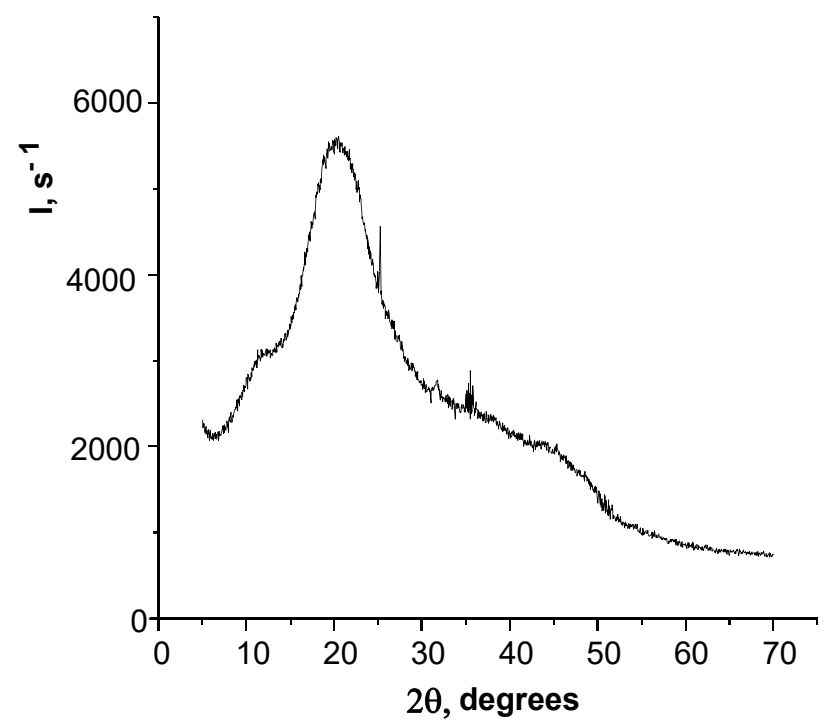

b

Figure 4. X-ray native starch (a) and adipic acid-modified chloride $(b)(n=3, p \leq 0,05)$ 


\section{- Food Technology -}

The native starch X-ray indicates its amorphous-crystalline structure with a crystallinity degree of $12 \%$. The modified starch has an amorphous structure with the crystallinity of only $5 \%$. In addition, the starch grains destruction primary structure was also confirmed by optical microscopy, as follows. Therefore, chemical modification with adipic acid chloride causes a decrease in the original starch crystal structure.

\section{Microscope research}

Native starch is in the grains form that can be seen under a microscope. For each species, depending on the origin, it has a different shape and size. Since in the process of modification there was a crosslinking of glucopyranose chains, so we can expect a change in the shape of the grains. The study results are shown in Figure 5.

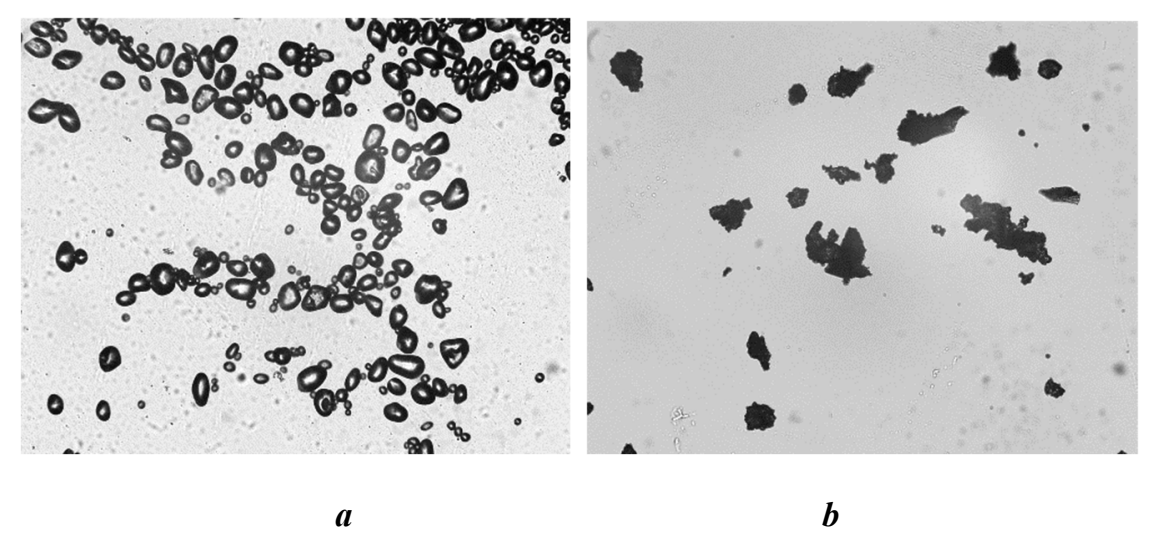

Figure 5. The type of grains of native (a) potato starch and modified with adipic acid chloride (b)

$(\times 400)$

Appearance (Figure 5) shows that the potato starch chemical modification by crosslinking, leads to the grains destruction of the initial shape. Therefore, the change in the external starch grains shape also confirms the chemical potato starch modification with adipic acid chloride.

\section{Application of the obtained modification product}

Starch as a natural polymer suitable for biodegradation (Lu D. R. et al., 2009; Versino F. 2016) is most widely used to create environmentally friendly packaging materials, using starch of different types: potato (Torabi Z. et al., 2013), corn, sago, cassava (Bangyekan C. et al., 2006; Bergo P. V. A. et al., 2009), oat (Galdeano M. C., 2013), pea (Han J. H., 2006), rice (Laohakunjit N. et al., 2004) or rice starch nanocrystals (Piyada K. et al., 2013), sweet potatoes (Mali S., 2002), bananas, mango (Romero-Bastida C. A., 2005), etc.

The proposed modification is due to the need to expand the range of raw materials (Shulga O.S. et al., 2017) for environmentally friendly packaging materials. 


\section{- Food Technology -}

We have already carried out a number of natural polymers modifications (Shulga O. S. et al., 2016), which have given positive results in obtaining environmentally friendly materials from them (Fan, Y. et al., 2020). From the obtained product modifications will receive films that can be used for food packaging.

\section{Conclusions}

1. The potato starch modification with adipic acid chloride was performed, which was confirmed by elemental analysis.

2. There were changes in the frequency bands of native starch in the uncharacteristic region in the IR spectra: the frequency of oscillations at $981.81 \mathrm{~cm}^{-1}$ increased and in the modified starch lies spectrum at $1023.75 \mathrm{~cm}^{-1}$, the band with a frequency of $763.63 \mathrm{~cm}^{-}$ ${ }^{1}$ shifted to $912.93 \mathrm{~cm}^{-1}$, and the band with an oscillation frequency of $573.42 \mathrm{~cm}^{-1}$ shifted to $631.13 \mathrm{~cm}^{-1}$, indicating a change in the uncharacteristic region of the native starch after acylation spectrum.

3. NMR confirmed the crosslinking of glucopyranose chains as well as elemental analysis.

4. The obtained modified product properties were studied and it was found that the modification changed the moisture bonds shape with starch, the grains appearance, the crystallinity degree decreased from 12 to $5 \%$.

5. The obtained modified product will be used as raw material for the production of environmentally friendly packaging materials.

\section{References}

Aburto J., Alric I., Borredon E. (1999), Preparation of Long-chain Esters of Starch Using Fatty Acid Chlorides in the Absence of an Organic Solvent, Starch-Starke, 51(4), pp. 132-135.

Bangyekan C., Aht-Ong D., Srikulkit K. (2006), Preparation and properties evaluation of chitosan-coated cassava starch films, Carbohydrate Polymers, 63(1), pp. 61-71.

Bergo P. V. A., Sobral P. J. A., Prison J. M. (2009), Physical properties of cassava starch films containing glycerol, Food Engineering Dept., FZEA, University of Sao Paulo, Brazil. Received. 8, pp. 1-6.

Bhosale R., Singhal R. (2006), Process optimization for the synthesis of octenyl succinyl derivative of waxy corn and amaranth starches, Carbohydrate Polymers, 66(4), pp. 521-527.

Chorna A. I., L. Iu. Arsenieva, Shulga O. S. (2016), Yistivni plivky - perspektyvnyi napriam pakovannia kharchovykh produktiv, Visnyk Lvivskoi komertsiinoi akademii, 16, pp. 8185.

Chung C., Lee M., \& Choe E. K. (2004), Characterization of cotton fabric scouring by FTIR ATR spectroscopy, Carbohydrate Polymers, 58(4), pp. 417-420.

Fan, Y. \& Picchioni F. (2020), Modification of starch: A review on the application of «green» solvents and controlled functionalization, Carbohydrate Polymers, 241, 116350.

Fathi F., Namazi H. (2014), Characterization and solvent free-synthesis of modified potato starch, Journal of Materials Science and Chemical Engineering, 2, pp. 11-15.

Galdeano M. C. (2013), Influence of thickness on properties of plasticized oat starch films, Brazilian Archives of Biology and Technology, 56(4), pp. 637-644. 
Han J. H. (2006), Physical and mechanical properties of pea starch edible films containing beeswax emulsions, Journal of Food Science, 71(6), pp. 290-296.

Hui Chi et al. (2008), Effect of acetylation on the properties of corn starch, Food Chemistry, 106 (3), pp. 923-928.

Junistia L. et al. (2008), Synthesis of higher fatty acid starch esters using vinyl laurate and stearate as reactants, Starch-Stärke, 60(12), pp. 667-675.

Kryazhev V. N., Romanov V. V., Shirokov V. A. (2010), Poslednie dostizheniya himii i tekhnologii proizvodnyh krahmala, Himiya rastitel'nogo syr'ya, 1, pp. 5-12.

Laohakunjit N., Noomhorm A. (2004), Effect of plasticizers on mechanical and barrier properties of rice starch film, Starch-Stärke, 56(8), pp. 348-356.

Lu D. R., Xiao C. M., Xu S. J. (2009), Starch-based completely biodegradable polymer materials, Express polymer letters, 3(6), pp. 366-375.

Mali S. (2002), Microstructural characterization of yam starch films, Carbohydrate Polymers, 50(4), pp. 379-386.

Namazi H., \& Dadkhah A. (2010), Convenient method for preparation of hydrophobically modified starch nanocrystals with using fatty acids, Carbohydrate Polymers, 79(3), pp.731-737.

Piyada K., Waranyou S., Thawien W. (2013), Mechanical, thermal and structural properties of rice starch films reinforced with rice starch nanocrystals, International Food Research Journal, 20(1), pp. 439-449.

Prime R. B., Bair H. E., Vyazovkin S., Gallagher P. K., Riga, A. (2009), Thermogravimetric analysis (TGA), Thermal analysis of polymers: Fundamentals and applications, pp. 241-317.

Romero-Bastida C. A. (2005), Physicochemical and microstructural characterization of films prepared by thermal and cold gelatinization from non-conventional sources of starches, Carbohydrate Polymers, 60(2), pp. 235-244.

Shulga O. S. ta in. (2017), Modyfikatsiia pektynu yak plivkoutvoriuvacha dlia yistivnykh plivok khlibobulochnykh i kondyterskykh vyrobiv, Prohresyvni tekhnika ta tekhnolohii kharchovykh vyrobnytstv restorannoho hospodarstva i torhivli, 1(25), pp. 220-233.

Shulga O.S. et al. (2018), Modyfikatsiia kartoplianoho krokhmaliu khloranhidrydom propionovoi kysloty ta fizyko-khimichni doslidzhennia oderzhanoho produktu, Voprosy khimii i khimicheskoi tekhnologii, 2, pp. 128-136.

Shulga O.S., Chorna A.I. (2017), Dekstrini Shardingera yak sirovina dlya ïstivnih plivok ta pokrittiv, Naukovi praci NUHT, 23(5, 2), pp. 116-124.

Shulga O. et al. (2018), Modification of Potato Starch by Acetylmalic Acid Chloroanhydride and Physicochemical Research of the New Product, International Journal of Polymer Science, Available at: https://www.hindawi.com/journals/ijps/2018/7253656/abs/.

Shulga O. S., Chorna A. I., Arsenieva L. Y., Hol A. O. (2016), Edible coating as factor of preserving freshness and increasing biological value of gingerbread cakes, Food science and technology, 10(4), pp. 9-13.

Silversteyn R., Vebster F., Kiml D. (2011), Spektrometricheskaya identifikatsiya organicheskih soedineniy, Moscow.

Suvorova A. I., Tyukova I. S., Trufanova E. I. (2000), Biorazlagaemyie polimernyie materialyi na osnove krahmala, Uspehi himii, 69(5), pp. 494-504.

Torabi Z., Mohammadi A. (2013), Nafchi The effects of $\mathrm{SiO}_{2}$ nanoparticles on mechanical and physicochemical properties of potato starch films, Journal of Chemical Health Risks, 3(1), pp. 33-42.

Versino F. (2016), Starch-based films and food coatings: An overview, Starch-Stärke, 68(1112), pp. 1026-1037. 